\title{
Composite lengthened arterial conduits: Long-term angiographic results of an uncommon surgical strategy
}

Giuseppe Vitolla, MD

Gabriele Di Giammarco, MD

Giovanni Teodori, MD

Valerio Mazzei, MD

Carlo Canosa, MD

Michele Di Mauro, MD

Stefano D'Alessandro, MD

Antonio Maria Calafiore, MD
From the Department of Cardiac Surgery, G. D'Annunzio University, Chieti, Italy.

Received for publication Jan 8, 2001; revisions requested Feb 26, 2001; revision received March 26, 2001; accepted for publication March 28, 2001.

Address for reprints: Antonio Maria Calafiore, MD, G. D’Annunzio University, Department of Cardiac Surgery, S. Camillo de' Lellis Hospital, Via C. Forlanini, 50, 66100 Chieti, Italy (E-mail: calafiore@ unich.it).

J Thorac Cardiovasc Surg 2001;122:687-90

Copyright (C) 2001 by The American Association for Thoracic Surgery

0022-5223/2001 $\$ 35.00+0 \quad \mathbf{1 2 / 1 / 1 1 6 2 1 1}$

doi:10.1067/mtc.2001.116211
Background: We sought to evaluate the long-term patency rate of composite lengthened conduits.

Methods and Results: From December 1991 to April 2000, 43 patients had a composite lengthened arterial conduit. There was a mean of $2.83 \pm 1.23$ anastomoses per patient. No 30-day mortality occurred. Five patients died from 3 to 84 months after the operation (mean, $38.6 \pm 34.6$ months). After a mean follow-up of $57.0 \pm$ 32.3 months (range, 3-99 months), all the survivors are asymptomatic. The only cardiac major events recorded were $2(4.6 \%)$ late acute myocardial infarctions in the patients who died. Eight-year survival and event-free survival were both $80.4 \% \pm$ $9.1 \%$ (range, $3 \%-93 \%$ ). In the early period ( $13.5 \pm 4.8$ days) in 26 patients, 26 arterial composite lengthened conduits and 37 distal anastomoses had postoperative angiographic control; all the anastomoses were rates as grade A, according to Fitzgibbon classification. In the late period ( $29 \pm 30$ months) in 23 patients, 23 arterial composite lengthened conduits and 34 distal anastomoses were checked; the patency rate was $22(95.6 \%)$ of 23 for the composite lengthened conduits and 33 $(97 \%)$ of 34 for the distal anastomoses.

Conclusions: In particular situations, when the length of an arterial conduit is not enough to allow a correct use of the graft, lengthening of an arterial conduit can be a safe and effective technique.

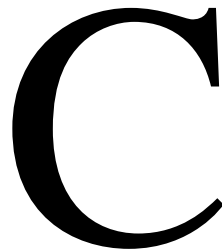

omposite arterial grafting has been described by many authors ${ }^{1-4}$ but mainly as a T or Y graft. The possibility of lengthening an arterial conduit (AC) with another $\mathrm{AC}$ (composite lengthened conduit [CLC]) has seldom been explored and only when related to the technical feasibility in the left anterior small thoracotomy procedure. $^{5}$

We reviewed our long-term experience with this strategy, which, in selected cases, represents an effective solution to reach distant target anastomotic sites.

\section{Patients and Methods}

From December 1991 to April 2000, 43 patients (1.3\% of the patients submitted to myocardial revascularization in the same period of time) underwent isolated myocardial revascularization through a median sternotomy by using a composite arterial lengthened conduit. Indications to this strategy were mainly the impossibility for an arterial graft (in situ or anastomosed to the proximal aorta) to reach the target coronary vessel because of reduced length or because of injury during harvesting that forced exclusion of part of the graft. 


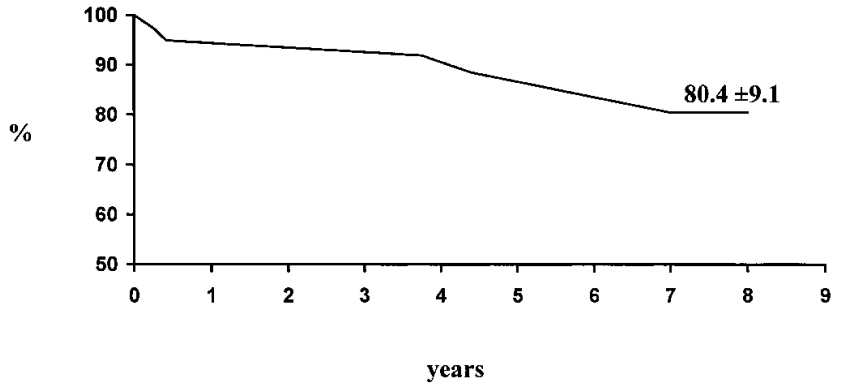

Figure 1. Actuarial survival and event-free survival.

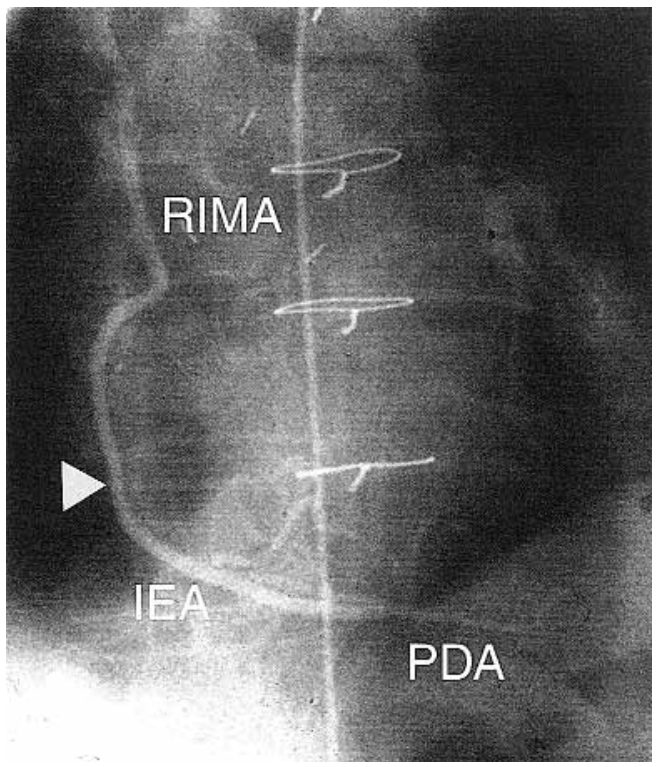

Figure 2. Late follow-up angiogram (8 years and 9 months). Arrow shows end-to-end anastomosis between right ITA (RIMA) and inferior epigastric artery (IEA) grafted to posterior descending artery (PDA).

Preoperative data are shown in Table 1.

In $41(95.4 \%)$ patients the donor $\mathrm{AC}$ was an internal thoracic artery (ITA; pedicled in 22 and skeletonized in 19), and a radial artery was used in $2(4.6 \%)$ patients. The second conduit was an ITA in 6 patients (pedicled in 2 and skeletonized in 4), a radial artery in 22 patients, and an inferior epigastric artery in 15 patients.

\section{Surgical Technique}

Harvesting of the ITA and of the radial and epigastric arteries was previously described. ${ }^{6}$ The lengthening conduit was connected to the donor conduit with an end-to-end anastomosis before starting the procedure. The surgical technique has been previously reported. 5,7

It is necessary to put the CLC over the heart to avoid any distortion of the graft. As a result of inner pressure, the graft will always be suitably oriented. If there is any doubt, methylene blue
TABLE 1. Preoperative data

\begin{tabular}{lc}
\hline Male/female & $34 / 9$ \\
Age (y) & $60.7 \pm 8.2$ \\
Elective/urgent & $28 / 15$ \\
LVEF (\%) & $60.5 \pm 12.4$ \\
Two-vessel disease & $7(16.2 \%)$ \\
Three-vessel disease & $36(83.7 \%)$ \\
LM & 0 \\
Redo operation & $5(11.6 \%)$ \\
\hline
\end{tabular}

Results are expressed as means \pm standard deviation unless otherwise indicated. $L V E F$, Left ventricular ejection fraction; $L M$, left main.

\section{TABLE 2. Arterial CLCs}

\begin{tabular}{lc}
\hline LITA + IEA & 5 \\
LITA + RITA & 4 \\
LITA + RA & 6 \\
RITA + IEA & 9 \\
RITA + LITA & 1 \\
RITA + RA & 16 \\
RA + IEA & 1 \\
RA + LITA & 1 \\
\hline LITA, Left ITA; IEA, inferior epigastric artery; RITA, right ITA; RA, radial \\
artery.
\end{tabular}

can be used to mark the right direction. As soon as the aorta was unclamped (or when the last anastomosis was accomplished without cardiopulmonary bypass [CPB]), a continuous infusion of diltiazem or nitroglycerin was begun and continued up to the first postoperative day, when oral diltiazem was started $(60 \mathrm{mg} 3$ times a day for 4 weeks).

From the operating theater, the patients were transferred to the intensive care unit, where they generally remained up to the first postoperative day, after which they were moved to the general ward.

\section{Follow-up}

All the patients were followed up in our outpatients clinic at 3,6, 12 months after the operation and every year thereafter. Clinical follow-up was $100 \%$ complete. Survival and survival free from cardiac events (ie, acute myocardial infarction or need to repeat interventional or surgical revascularizion) were considered. In all but one of the patients, angiography was performed electively.

\section{Statistical Analysis}

Results are expressed as means \pm standard deviation unless otherwise indicated. Survival and event-free survival curves were obtained with the Kaplan-Meier method (SPSS software; SPSS, Inc, Chicago, Ill).

\section{Results}

In 7 patients the myocardial revascularization was performed without $\mathrm{CPB}$. In the remaining patients the $\mathrm{CPB}$ 
TABLE 3. Distribution of the distal anastomoses performed with arterial CLCs

\begin{tabular}{|c|c|c|c|c|c|c|}
\hline & LAD & Diagonal & Circumflex system & RCA & PDA & Total \\
\hline LITA + IEA & - & 2 & 4 & - & - & 6 \\
\hline LITA + RITA & 2 & - & 1 & - & - & 3 \\
\hline LITA + RA & - & 1 & 7 & 1 & 1 & 10 \\
\hline RITA + IEA & 1 & - & 1 & 5 & 2 & 9 \\
\hline RITA + LITA & 1 & 1 & - & - & - & 2 \\
\hline RITA + RA & 3 & 1 & 14 & 1 & 6 & 25 \\
\hline $\mathrm{RA}+\mathrm{IEA}$ & - & - & 1 & - & - & 1 \\
\hline RA + LITA & 1 & - & - & - & - & 1 \\
\hline Total & 8 & 5 & 28 & 7 & 9 & 57 \\
\hline
\end{tabular}

$\angle A D$, Left anterior descending artery; $R C A$, right coronary artery; PDA, posterior descending artery; LITA, left ITA; IEA, inferior epigastric artery; RITA, right ITA; $R A$, radial artery.

TABLE 4. Postoperative follow-up angiograms

\begin{tabular}{lcc}
\hline & Early* $^{*}(\mathbf{n}=\mathbf{2 6})$ & Latet $(\mathbf{n}=\mathbf{2 3})$ \\
\hline Arterial CLC & & \\
Intermediate anastomosis & $26 / 26(100 \%)$ & $22 / 23(95.6 \%)$ \\
Distal anastomosis & $37 / 37(100 \%)$ & $33 / 34(97 \%)$ \\
LITA & $15 / 15(100 \%)$ & $13 / 13(100 \%)$ \\
RITA & $5 / 5(100 \%)$ & $4 / 4(100 \%)$ \\
RGEA & $2 / 2(100 \%)$ & $2 / 2(100 \%)$ \\
IEA & $12 / 12(100 \%)$ & $11 / 11(100 \%)$ \\
RA & $4 / 4(100 \%)$ & $3 / 3(100 \%)$ \\
SVG & $8 / 8(100 \%)$ & $7 / 7(100 \%)$ \\
\hline
\end{tabular}

LITA, Left ITA; RITA, right ITA; RGEA, right gastroepiploic artery; IEA, inferior epigastric artery; $R A$, radial artery; SVG, saphenous vein graft.

${ }^{*}$ Early $=13.5 \pm 4.8$ days (range, $5-28$ days).

tLate $=29 \pm 30$ months (range, 6-93 months).

time was $64.0 \pm 27.0$ minutes, and the aortic crossclamp time was $45.5 \pm 22.7$ minutes. In 43 patients a mean of 2.8 \pm 1.2 anastomoses were performed, and in $34(65 \%)$ patients a total arterial myocardial revascularization was carried out.

Table 2 shows the arrangement of lengthened conduits. In 43 patients the CLC was used for 57 distal anastomoses $(1.3 \pm 0.6)$; a sequential graft was performed 12 times. The distribution of the distal anastomoses is shown in Table 3.

After a mean of $28.7 \pm 16.5$ hours in the intensive care unit, all the patients were transferred to the general ward. After $10.5 \pm 10.9$ days, they were discharged home.

No patient died within 30 days from the operation. Only one $(2.3 \%)$ patient showed ventricular arrhythmias in the postoperative course, and these were treated with drug therapy. One patient had a wound-healing complication and required a surgical revision.

\section{Follow-up}

After a mean follow-up period of $57.0 \pm 32.3$ months (range, 3-99 months), 38 (88.4\%) patients are alive and asymptomatic without any major complications, such as acute myocardial infarction, redo operations, or interventional revascularization. Five late deaths were recorded, 2 as a result of cardiac causes (acute myocardial infarction 20 and 84 months after the operation, respectively) and 3 as a result of noncardiac causes ( 2 patients with gastric bleeding at 5 and 72 months after the operation, respectively, and the 1 patient with leukemia 56 months after the operation). The only major cardiac events recorded in the follow-up period were $2(4.6 \%)$ late acute myocardial infarctions that occurred in the patients who died.

Eight-year survival and event-free survival were both $80.4 \% \pm 9.1 \%$ (Figure 1).

\section{Follow-up Angiograms}

Twenty-six $(60.5 \%)$ patients had an early angiogram, and 23 $(60.5 \%)$ of the survivors had a late postoperative angiogram (Figure 2$)$. In the early period (13.5 \pm 4.8 days) 26 patients with arterial CLCs and 37 patients with distal anastomoses had a postoperative angiographic examinations; all the anastomoses were rated as grade A, according to the Fitzgibbon 
classification. ${ }^{8}$ Of $23(60.5 \%)$ patients who had late angiographic examinations ( $29 \pm 30$ months), only an ITA lengthened with a radial artery on the posterior descending artery was occluded because of progression of coronary disease. This patient had a postoperative angiogram after an abnormal myocardial scintiscan on the inferior wall. The patient at present is asymptomatic with medical treatment. Twentytwo $(95.6 \%)$ of 23 intermediate and $33(97.0 \%)$ of 34 distal anastomoses were rated as grade $\mathrm{A}$, according to the Fitzgibbon classification. The angiographic results of arterial CLC and of the other grafts used are shown in Table 4. The patency rate of the arterial CLC distal anastomoses in the early (37/37 [100\%]) and in the late (33/34 [95.6\%]) period are comparable with the ITA's patency rate (early, 20/20; late, 17/17; $P=$ not significant).

\section{Discussion}

In selected patients the possibility of lengthening an $\mathrm{AC}$ with another $\mathrm{AC}$ can be a technical solution when the donor graft is too short to reach the target coronary vessel. In previous reports, good long-term patency of the $\mathrm{Y}$ or $\mathrm{T}$ grafts was demonstrated. $1,3,9$ To the best of our knowledge, the results of arterial CLC anastomoses have not been evaluated, at least in the long term.

We reported our experience with arterial CLCs in the left anterior small thoracotomy operation, ${ }^{5}$ in which the left ITA was lengthened with the inferior epigastric artery. These patients had follow-up angiograms $87.5 \pm 23.3$ days after the operation, with a satisfying patency rate of $21(95.4 \%)$ of 22.

From this study, it was evident that the intermediate anastomosis between 2 ACs was not a weak point of the strategy of composite grafting and that its failure was rare.
Seldom is the surgeon forced to lengthen another AC because of the great availability of such conduits. However, when an AC is harvested, an injury can force the discarding of part of an in situ conduit, making its lengthening the only possible solution. Our study was able to demonstrate that, if necessary, lengthening of an AC can be a safe and effective technique.

\section{References}

1. Tector AJ, Amundsen S, Schmahl TM, Kress DC, Peter M. Total revascularization with T-grafts. Ann Thorac Surg. 1994;57:8-9.

2. Royse AG, Royse KL, Groves KL, Bus B, Yu G. Blood flow in composite arterial grafts and effect of native coronary flow. Ann Thorac Surg. 1999;68:1619-22.

3. Calafiore AM, Contini M, Vitolla G, Di Mauro M, Mazzei V, Teodori $\mathrm{G}$, et al. Bilateral internal thoracic artery grafting: long-term clinical and angiographic results of in situ versus $\mathrm{Y}$ grafts. J Thorac Cardiovasc Surg. 2000;120:990-8.

4. Barra JA, Mondine P, Malhab A, Mansourat J, Rukbi I, Blanc JJ, et al. Right internal mammary artery reimplantation into the left internal mammary artery. Y anastomosis. 25 cases. Ann Chir. 1991;45:661-6.

5. Calafiore AM, Teodori G, Di Giammarco G, Vitolla G, Contini M, Maddestra N, et al. Left internal mammary elongation with inferior epigastric artery in minimally invasive coronary surgery. Eur $J$ Cardiothorac Surg. 1997;12:393-6.

6. Calafiore AM, Di Giammarco G, Luciani N, Maddestra N, Di Nardo E, Angelini R. Composite arterial conduits for a wider arterial myocardial revascularization. Ann Thorac Surg. 1994;58:185-90.

7. Calafiore AM. Use of the inferior epigastric artery for coronary revascularization. Operative Technique Card Thorac Surg. 1996;1:47-59.

8. Fitzgibbon GM, Kafka HP, Leach AJ, Keon WJ, Hooper GD, Burton JR. Coronary bypass graft fate and patient outcome: angiographic follow-up of 5,065 grafts related to survival and re-operation in 1,388 patients during 25 years. J Am Coll Cardiol. 1996;28:616-26.

9. Weinschelbaum EE, Gabe ED, Macchia A, Smimmo R, Suarez LD. Total myocardial revascularization with arterial conduits: radial artery combined with internal thoracic artery. J Thorac Cardiovasc Surg. 1997;114:911-6. 